OPEN ACCESS

Edited by:

Rui Zhao,

National Research Council Canada (NRC-CNRC), Canada

Reviewed by:

Jichao Hong,

University of Science and Technology

China

Haijun Ruan,

Imperial College London,

United Kingdom

Zhiqiang Niu,

Loughborough University,

United Kingdom

*Correspondence:

Heesung Park

heesungpark@changwon.ac.kr

Specialty section:

This article was submitted to

Electrochemical Energy Conversion and Storage,

a section of the journal

Frontiers in Energy Research

Received: 07 December 2021

Accepted: 28 January 2022

Published: 07 March 2022

Citation:

Choi J and Park H (2022) Correlation

Between Changes in Environmental

Temperature and Performance of

High-Discharge Lithium-

Polymer Batteries.

Front. Energy Res. 10:830581. doi: $10.3389 /$ fenrg.2022.830581

\section{Correlation Between Changes in Environmental Temperature and Performance of High-Discharge Lithium-Polymer Batteries}

\author{
Jaehun Choi ${ }^{1}$ and Heesung Park ${ }^{2 *}$ \\ ${ }^{1}$ Smart Manufacturing Engineering Division, Graduate School of Mechanical Engineering, Changwon Nat'l Univ, Changwon, \\ South Korea, ${ }^{2}$ Department of Mechanical Engineering and Smart Manufacturing Engineering, Changwon Nat'l Univ, Changwon, \\ South Korea
}

Electric vehicles (EVs) have been developed to solve environmental problems and the depletion of energy resources, and batteries have been used as their main energy source. The battery used in this study was a lithium polymer battery with the same chemical structure as lithium-ion. The use of a solid electrolyte has advantages, such as lack of leakage of electrolyte, high density per size, and convenient shape design. In this study, we analyzed the heat generation and performance characteristics of EV batteries through experiments on changes in environmental temperature. There is a difference in the heat generation depending on the discharge rate, and the performance characteristics of the battery improves as the environmental temperature rises. In the experiment, the battery discharge performance and heat generation were meaningful at $40^{\circ} \mathrm{C}$ environmental temperature, the worst battery discharge performance and heat generation at $-30^{\circ} \mathrm{C}$ environmental temperature were $25.1 \mathrm{~W}(1 \mathrm{C}), 81.0 \mathrm{~W}(2 \mathrm{C})$, and $151.5 \mathrm{~W}(3 \mathrm{C})$. In this study, the heat generation and performance characteristics of the battery were analyzed according to the change in the environmental temperature and discharge rate of the battery. We proposed a relationship between heat generation and environmental temperature in terms of discharge rate. The relationship is significant in designing thermal management system for battery powered devices.

\section{Keywords: Li-polymer battery, environmental temperature, temperature variation, heat generation, battery} performance, experimental evaluation

\section{INTRODUCTION}

Electric vehicles (EVs), hybrid EVs, and plug-in hybrid EVs are gradually being developed because of the depletion of energy resources and increasing environmental pollution worldwide (Amjad et al., 2010]. The global market for EVs increased from 1 million in 2014 to approximately 7.2 million in 2019 and is expected to reach 116 million by 2030 , therefore, the rapid growth of this industry is associated with a significant decrease in the cost of lithium-ion batteries (LIBs) over the past decade (International Energy Agency, 2020; McKerracher, 2020). Additionally, studies on performance and lifespan are required to further improve the economic and environmental costs associated with LIBs (Li et al., 2018).

Among the various types of EV battery packs, LIBs are being used because of their high energy density, long cycle life, light weight, and lack of memory effect (Bahiraei et al., 2017; Requia et al., 
2018). In addition, the lithium-polymer battery has the same structure as the LIB and uses a gel-type polymer electrolyte; therefore, there is neither leakage and large capacity nor natural discharge and memory effect. It is also applied to EVs because it has the advantage of easy shape design using thin aluminum and plastic coated film. For lithium-polymer batteries and LIBs, electrical problems may occur when voltage, current, and power limits are exceeded during charging/discharging, and a fire may occur because of the external shock or internal heat. Therefore, it is necessary to improve the performance by studying the risk factors for battery life and safety (Panchal et al., 2018). The battery management system is used to protect a battery from risk factors, such as thermal runaway, to maintain an optimum temperature range of $15-40^{\circ} \mathrm{C}$, and to maintain a temperature difference between the batteries within $5^{\circ} \mathrm{C}$ (Al-Zareer et al., 2018).

Various studies have been conducted to improve the battery performance of LIBs and lithium-polymer batteries by controlling the risk factors. Typically, one of the studies shows how to maintain the performance of the battery by controlling the heat of the battery. The control method includes an air cooling type, a water cooling type, a phase change material (PCM), and a hybrid type.

They performed a three-dimensional numerical investigation of the transient thermal behavior of LIB modules using a userdefined function (UDF) to formulate the heating generation of the battery cell. They concluded that in the designed battery module, different air temperature profiles appear depending on the flow direction and the width and depth of the module, and by determining where the highest temperature occurs, the flow pattern in the battery module depends on the depth of the battery (Jilte and Kumar, 2018). They conducted a CFD coupled multi-objective optimization approach for an air cooling BTMS with spoilers. By applying a spoiler to the battery gap of the air-cooled BTMS, the airflow path was changed, effectively improving the temperature uniformity of the battery module, and the difference in cooling performance was investigated according to the shape, number, and length of the spoiler (Wang et al., 2021). In the study of applying the air cooling method in the battery thermal management system, the application to the change of the battery electrical performance according to the environmental temperature by focusing only on the cooling performance of the battery is insufficient.

They performed a three-dimensional numerical analysis of a high-discharge-rate 20-Ah lithium-ion pouch cell with U-turn microchannel cooling plates on both sides. Through various variables of different coolant temperatures, inlet coolant mass flow rates, the number of cooling channels, maximum channel width, and flow patterns, the numerical analysis results were verified as experimental research results within $8.5 \%$ by reflecting the exothermic rate calculated in the proposed method (Patil et al., 2020). They investigated a lightweight liquid cooling solution for cooling a prismatic hard case cell. They concluded that the effect of fluid flow direction, flow velocity, channel dimension, and cooling medium on the heat distribution of the cell, and the cooling performance and lightweight results are highly feasible for controlling the heat distribution of battery packs comprising prismatic hard case LFP cells (Sheng et al., 2021). They experimentally investigated the thermal performance of water-cooled cold plates used in the thermal management of batteries using a conventional serpentine tube and mini channel designs, including a lithium-ion phosphate battery under certain discharge rates. They concluded that the use of the mini-channel cooling plate improved the thermal performance of the proposed mini-channel cooling plate through a further decrease in the maximum average battery surface temperature compared to the serpentine surface temperature and improved battery surface temperature uniformity (Kalkan et al., 2021). They numerically studied a straight mini-channel-based cold plate sandwiched between two consecutive batteries to form a battery module. They proposed a system with suitable cooling performance based on various design and operating conditions, such as mini-channel width, number of channels, coolant type, liquid flow rate, coolant temperature, ambient temperature, and discharge rate (Monika et al., 2021). Even in the study of the application of water cooling in the battery thermal management system, the application of the electrical performance of the battery that changes according to the environmental temperature is insufficient, focusing only on the battery cooling performance. It is necessary to maximize the efficiency of various cooling methods through the application of data on the electrical performance and heat generation of the battery in various environmental temperatures.

They investigated the modeling and analysis of a battery module to improve the thermal performance of the LIBs in EVs with phase change materials (PCMs). They identified expanded graphite as the best phase change material that will enhance the heat transfer rate increased when compared with the model without PCM, and concluded that high thermal conductivity is preferred for various environmental conditions, which will improve the battery performance with less voltage drop (Talluri et al., 2020). They conducted numerical simulations and experiments on the thermal performance of a battery module by adopting phase change cooling with PCM. They indicated that a higher thermal conductivity and latent heat leads to better thermal management performance considering the maximum temperature and temperature uniformity of the LIB module and concluded that thermal management performance slightly increased when the thermal conductivity and latent heat attained a relatively high value (Huang et al., 2020). They evaluated the performance of a passive thermal management system for high power LIBs in a cold environment. It was concluded that the low thermal conductivity of paraffin wax, which is considered detrimental at high temperatures to prevent overheating of the battery, provides advantages during short coldsoaking by keeping the module warm and improving energy (Ghadbeigi et al., 2018). They proposed a paraffin/expanded graphite (EG) composites-based battery module (PCM module), as well as a two-dimensional thermal model. They designed the optimal mass fraction of EG and a novel pyrolytic graphite sheet (PGS) reinforced paraffin/EG composite material-based battery module (PCM/PGS module) for the best thermal performance and found that PCM/PGS modules exhibit much better heat dissipation performance and temperature uniformity than PCM modules during discharge-charging cycles 
(Wu et al., 2017). In the study applying PCM in a battery thermal management system, it was analyzed that the battery performance was improved with a small voltage drop due to high thermal conductivity under various environmental conditions, and the electrical performance of the battery was also analyzed in a cold environment. For effective battery temperature management, it is necessary to analyze the additional environmental temperature and the weight of the cooling system.

They experimentally studied the hybrid cooling concept with enhanced water vaporization by convection and coolant. They demonstrated the excellence of hybrid cooling through comparison of non-cooling, water cooling, and hybrid cooling using fiber materials acting by capillary effects that do not require pumps, tubes, and heat exchangers for cooling water recirculation (Wei and AgelinChaab, 2018). They numerically studied and proposed a delayed cooling system coupling composite phase change material (CPCM) and nano phase change material emulsion (NPCME) to improve the working performance of LIBs under long-term charge-discharge cycles. They suggested that the NPCME/CPCM system can control the maximum temperature change with improved cooling performance and a lower flow rate than the conventional hybrid water/ CPCM system under optimal operating conditions (Cao et al., 2021). They proposed a thermal management method for a novel battery module involving an integrated design of PCM and cooling plate to prevent heat propagation and thermal runaway in a battery module made of 18,650 cells that have been damaged by nail penetration of up to three cells (Kshetrimayum et al., 2019). They proposed a novel dielectric fluid immersion cooling (DFIC) technology for LIB thermal management compared with four different cooling methods: natural convection, battery immersed in stationary dielectric fluid without tab cooling, battery immersed in a stationary dielectric fluid with tab cooling, and battery immersed in flowing dielectric fluid with tab cooling (Patil et al., 2021). In the study of applying the hybrid method in the battery thermal management system, the method combining various cooling methods is excessive to control only the maximum temperature of the battery. It is necessary to analyze and apply the correlation of battery electrical performance change with environmental temperature change. As a comprehensive cooling method is applied, efficiency and optimum temperature control conditions are required.

To maintain and improve battery system performance, various studies are being conducted on single cooling (air cooling, water cooling, and PCM application) and comprehensive cooling (hybrid cooling). In many cases, the papers on the thermal management system of the conventional battery conduct numerical analysis intensively on cooling technologies with the heat generation obtained through a single experiment of the battery. It is necessary to apply an optimal cooling effect by analyzing the electrical performance of the battery according to the environmental temperature and discharge rate of the battery. In this study, the battery performance

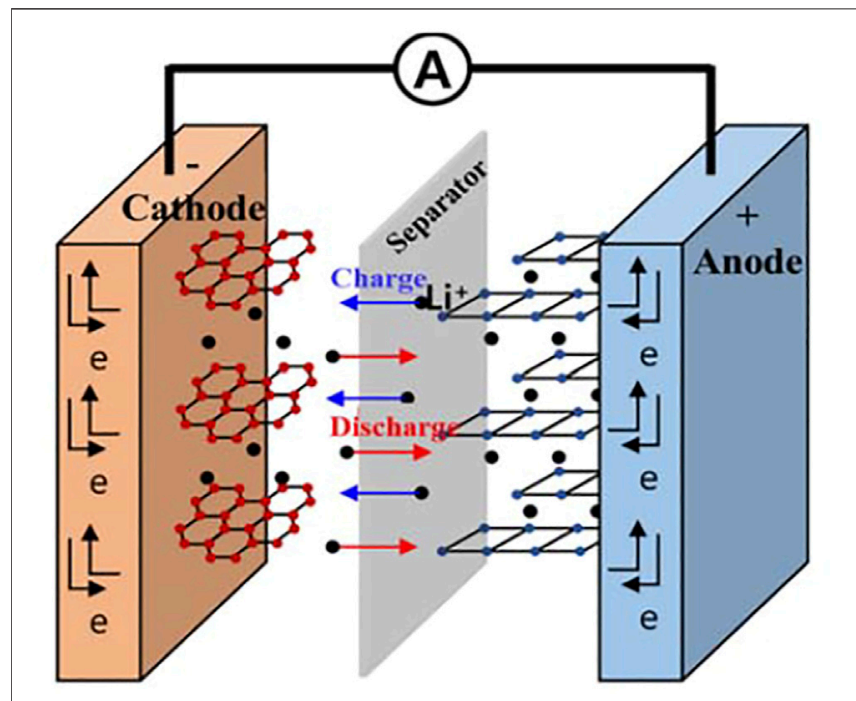

FIGURE 1 | Lithium-polymer electrochemical working principle.

according to changes in environmental temperature and discharge rate for a single cell of a lithium polymer battery before composing a battery system is analyzed as a basic study for future battery module research.

\section{THEORY}

Lithium-polymer batteries convert chemical energy into electrical energy through oxidation/reduction reactions between the positive and negative electrodes, and the general electrochemical principle for charge/discharge is achieved through Eq. 1 as shown in Figure 1.

$$
\mathrm{LiCoO}_{2}+\mathrm{C} \underset{\text { Charge }}{\stackrel{\text { Discharge }}{\rightleftarrows}} \mathrm{Li}_{i}-x \mathrm{CoO}_{2}+\mathrm{LixC}
$$

When charging/discharging, it is important to operate a lithium-polymer battery at an optimal environmental temperature because the internal resistance changes according to the temperature change of the battery, and power loss occurs because of the voltage drop. The voltage of the battery is determined by the current, time, and temperature as shown in Eq. 2; the amount of heat generation is shown in Eq. 3.

$$
\begin{gathered}
V_{\text {cell }}=f(I, t, T) \\
\dot{q}(\mathrm{~W})=I\left(U-V_{\text {Cell }}\right)-I\left(T \frac{d U}{d T}\right)
\end{gathered}
$$

Here, $I$ is current, $U$ is the open-circuit voltage (OCV), $V_{\text {Cell }}$ is the cell voltage, and $T$ is the temperature $(K)$. The $-I\left(T \frac{d U}{d T}\right)$ term represents reversible heat generation and the $I\left(U-V_{\text {Cell }}\right)$ term represents irreversible heat generation (Zhang et al., 2014). The increase in the temperature of the battery was proportional to the increase in the discharge rate. 
TABLE 1 | Specifications of Li-polymer battery.

\begin{tabular}{lc} 
Mechanical cell specifications & Value \\
\hline Cell size $(\mathrm{mm})$ & $187 \times 187 \times 11$ \\
Weight $(\mathrm{kg})$ & 0.785 \\
Nominal voltage $(\mathrm{M})$ & 3.7 \\
Full charge voltage $(\mathrm{V})$ & 4.2 \\
Nominal capacity (Ah) & 40 \\
Specific energy $(\mathrm{Wh} / \mathrm{kg})$ & 188.5 \\
Maximum charge rate & $1 \mathrm{C} \mathrm{(40} \mathrm{A)}$ \\
Maximum discharge rate & $3 \mathrm{C}$
\end{tabular}

The irreversible heat generation $q_{i r r}$ and the reversible heat generation $q_{\text {rev }}$ can be expressed by Eqs 4, 5, and the total heat generation $\dot{q}$ can be expressed by Eq. 6 (Jeon and Baek, 2011).

$$
\begin{gathered}
q_{i r r}(\mathrm{~W})=I\left(U-V_{\text {cell }}\right)=\frac{I^{2}}{\sigma} \\
q_{r e v}(\mathrm{~W})=-I\left(T \frac{d U}{d T}\right)=-T \Delta S \frac{I}{n F} \\
\dot{q}(\mathrm{~W})=\dot{q}_{i r r}+\dot{q}_{r e v}=\frac{I^{2}}{\sigma}-T \Delta S \frac{I}{n F}
\end{gathered}
$$

Here, $\sigma(S / m)$ is the electrical conductivity, $\Delta S\left(\mathrm{~W}^{\circ} \mathrm{C}^{-1}\right)$ is the change in entropy, $n$ is the charge number for the electrical reaction, and $F(96485 \mathrm{C} / \mathrm{mol})$ is the Faraday constant. Using these equations, the heat generation by the change in the environmental temperature and discharge rate of the lithium polymer battery was calculated.

\section{EXPERIMENT}

The discharge test of a high-discharge lithium-polymer battery was conducted based on the environmental temperature and discharge rate. Table 1 lists the mechanical and electrical characteristics of the batteries. The charging and discharging rates of the battery were determined according to the battery specifications. The maximum allowable charge current and maximum sustained discharges were $1 \mathrm{C}(40 \mathrm{~A})$ and $3 \mathrm{C}(120 \mathrm{~A})$, respectively. The configuration of the experimental equipment, the point of thermocouples installed on each side to analyze the temperature change on the surface of the battery and the lithium-polymer battery dimension size are described in detail in Figure 2. The 1) $40 \mathrm{Ah}$ Lithium-polymer battery, 2) Environmental chamber (TH3$\left.\mathrm{KE},-40-150^{\circ} \mathrm{C}\right)$, 3) Power supply (10kW (50V, 200A)), 4) Electronic load device (DC Electronic load 34106C), 5) Data collection (NI 9214), 6) Control device (Devices and controllers that record LabVIEW-related data are connected to a computer) were configured to conduct the battery environmental temperature and discharge experiments. As for the test method, the battery was fully charged with a Constant Current (CC), and when the temperature of the battery was adjusted by setting the environmental temperature, the discharge experiment was performed from

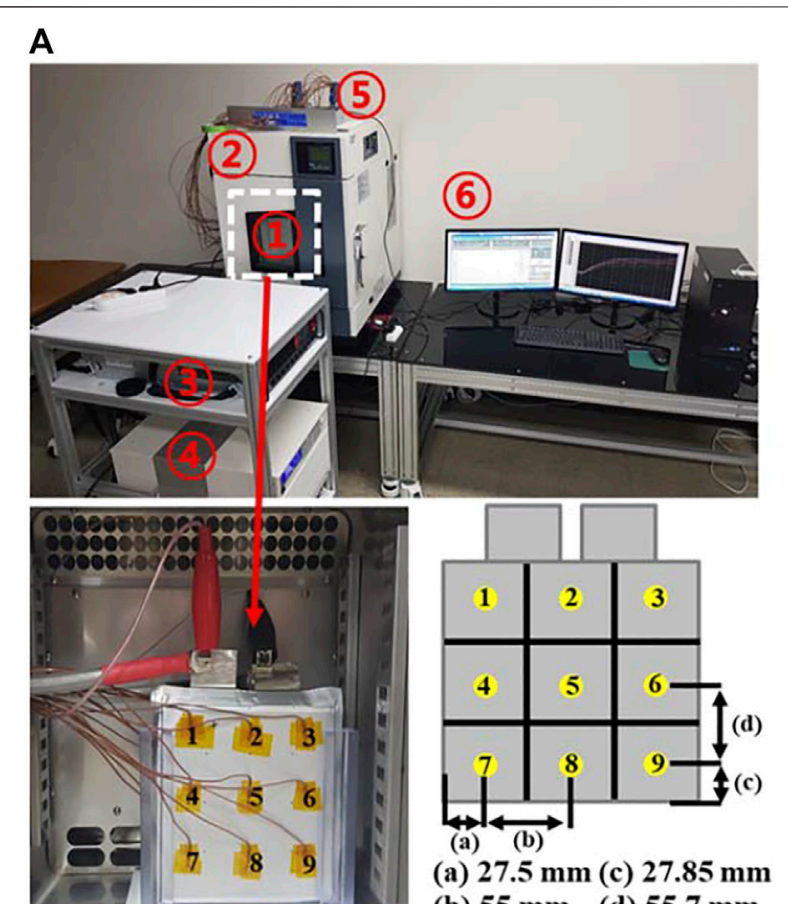

(b) $55 \mathrm{~mm} \quad$ (d) $55.7 \mathrm{~mm}$

Experiment set up and thermocouple point

B

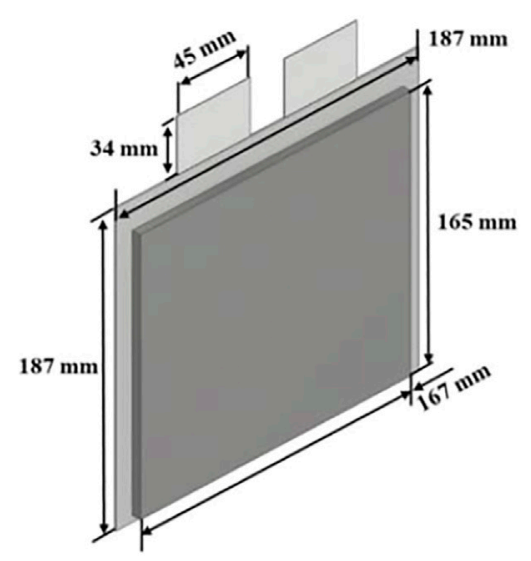

Lithium-polymer battery dimension size

FIGURE 2 | Configuration of experimental equipment and lithiumpolymer battery. (A) Experiment set up and thermocouple point, (B) Lithium-polymer battery dimension size.

TABLE 2 | Variables applied in the experiment test. 




1 C-rate

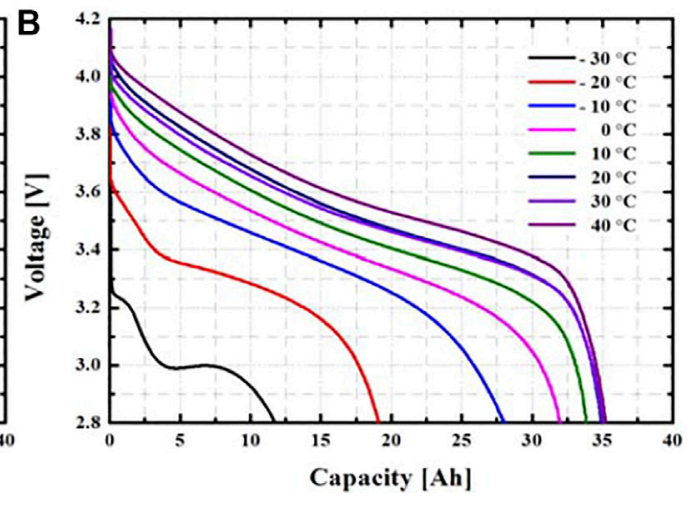

2 C-rate

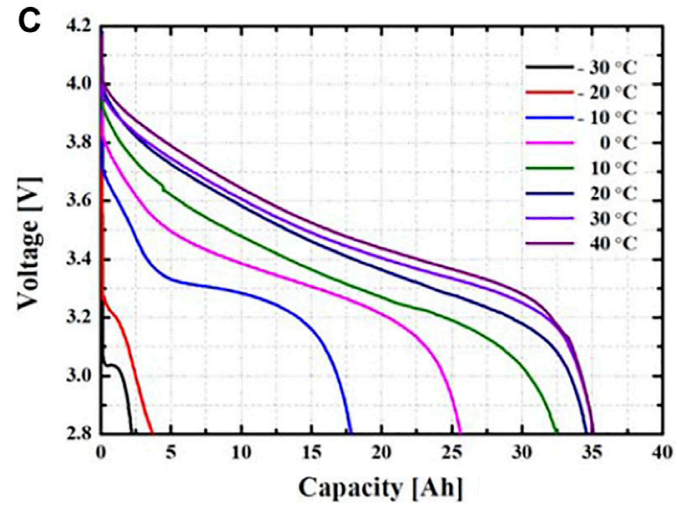

3 C-rate

FIGURE 3 | Discharge voltage according to environmental temperature change at each discharge rate. (A) 1 C-rate. (B) 2 C-rate. (C) 3 C-rate.

4.2 to $2.8 \mathrm{~V}$. A fully charged battery showed a decrease in voltage while reaching the environmental temperature set in the environmental chamber, but the experimental start conditions were similar. During discharge, T-type thermocouples were installed in 9 points at equal positions on the forward and back sides of the battery to measure the temperature change of the battery surface during discharging, and data on the surface temperature change were collected from 18 points. After the discharge experiment, a sufficient rest (up to $3 \mathrm{~h}$ ) time was applied to adjust the battery temperature to the environmental temperature of the room temperature, and the battery was recharged to experiment according to the environmental temperature and discharge rate. Table 2 lists the variables used in the experiment. Battery performance and battery surface temperature change were analyzed through a total of 24 experiments with 3 discharge rates $(1,2,3 \mathrm{C})$ and 8 environmental temperatures (in units of $10^{\circ} \mathrm{C}$ from $-30-40^{\circ} \mathrm{C}$ ). The experiment was not conducted considering the thermal runaway of the battery when the environmental temperature exceeded $40^{\circ} \mathrm{C}$.

\section{RESULT AND DISCUSSION}

\section{Effects of Environmental Temperature}

The following results were obtained through experiments on the performance and heat generation of high-discharge lithiumpolymer batteries owing to changes in the environmental temperature and discharge rate.

Figure 3 shows the change in the discharge voltage of the battery according to the environmental temperature change and discharge rate. Battery performance according to environmental temperature and discharge rate has a high effect at low temperatures and high discharge rates. At a discharge rate of $1 \mathrm{C}$, the effect on the environmental temperature was lower than that of other discharge rates, and in the low environmental temperature, the effect on the performance of the battery gradually increased. At discharge rates of 2 and $3 \mathrm{C}$, the lower the environmental temperature, the greater the effect on the battery performance, and it was found that the normal operation of the battery was difficult. The higher the environmental temperature, the better the battery performance 


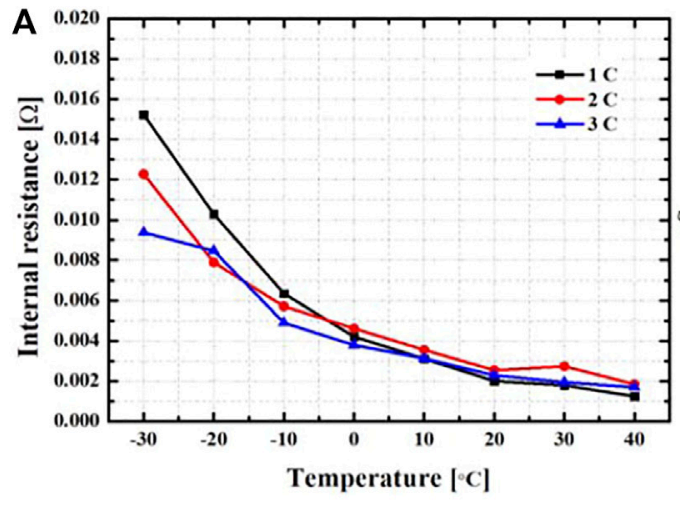

Averaged internal resistance change

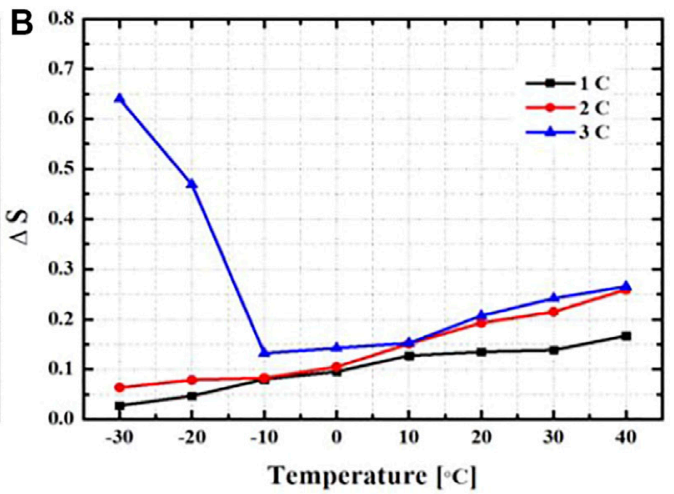

Averaged entropy change

FIGURE 4 | Averaged internal resistance and entropy change on the battery. (A) Averaged internal resistance change. (B) Averaged entropy change.

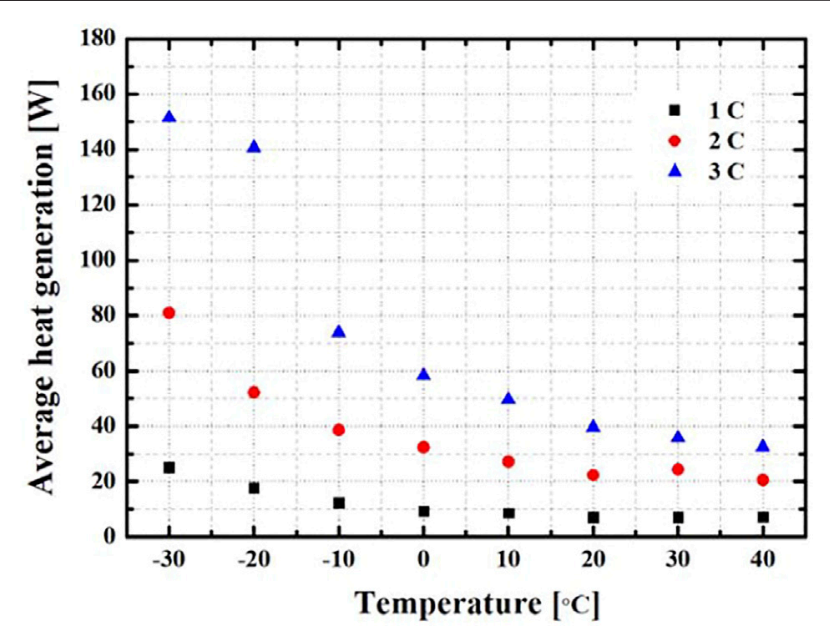

FIGURE 5 | Averaged heat generation on the surface of the battery.

at each discharge rate, and the lower the difference in battery performance.

Figure 4 shows the average internal resistance and average entropy change according to the change in the environmental temperature and discharge rate. The average internal resistance, which is related to the irreversible heat generation in Eq. 4 and Figure 4A, was found to be related to the temperature change. The internal resistance value was calculated in relation to the square value of the applied current in the battery discharge experiment in the irreversible calorific value Equation 4 $\left[I\left(U-V_{\text {cell }}\right)\right]$. Changes in environmental temperature affect the charge movement inside the battery, and it has been shown that the internal resistance decreases as the environmental temperature increases (Baronti et al., 2010). The entropy change related to the reversible heat generation as shown in Eq. 5 and Figure 4B was measured in the order of the

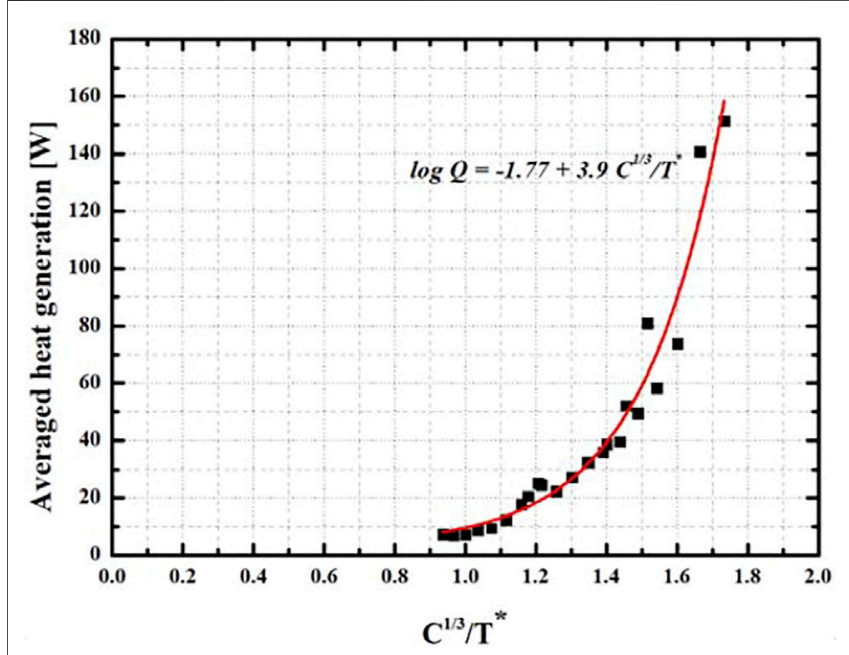

FIGURE 6 | The resulting heat generation versus. $\frac{C^{\frac{1}{3}}}{T^{*}}$

smallest surface average temperature change. The entropy change was calculated inversely by first calculating the reversible heat generation in Eq. 5, and assuming the charge number for the electrical reactions $(n=1)$ and the Faraday constant $(96485 \mathrm{C} /$ $\mathrm{mol}$ ) in the term $-T \Delta S \frac{I}{n F}$. At discharge rates of 1 and $2 \mathrm{C}$, the entropy change tended to increase as the environmental temperature increased, and it was calculated to be the highest at an environmental temperature of $40^{\circ} \mathrm{C}$. At a discharge rate of $3 \mathrm{C}$, the instantaneous entropy change was calculated to be high because the average temperature change was smaller than that of other environmental temperatures owing to the rapid discharge at $-20,-30^{\circ} \mathrm{C}$. When the environmental temperature rises, the entropy change also tends to increase in the same process.

Figure 5 shows the average heat generation according to the environmental temperature and discharge rate. There are differences in battery performance according to the discharge 


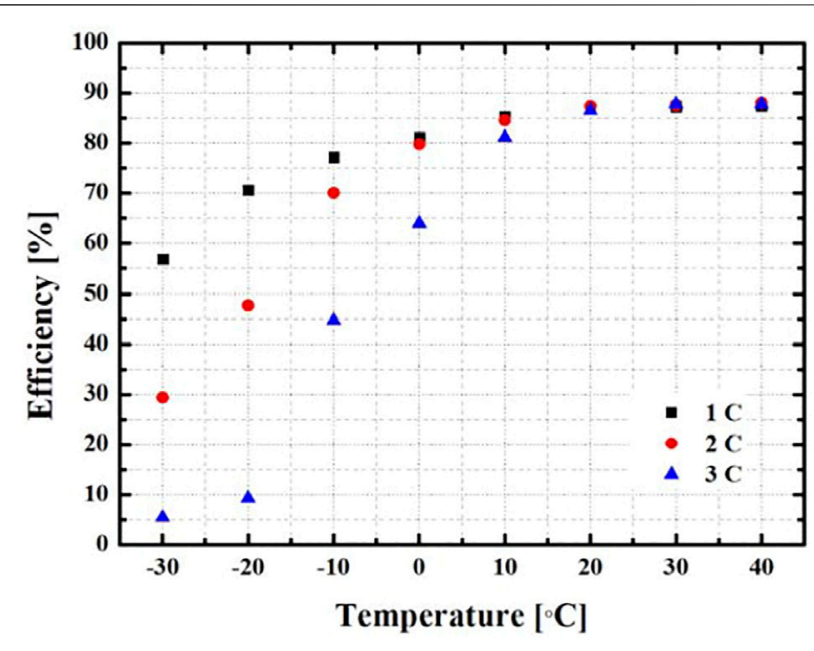

FIGURE 7 | Discharge efficiency according to the environmental temperature change.

rate and measured $\mathrm{OCV}$ at the environmental temperature. Based on an OCV value, the heat generation was calculated with different environmental temperatures by using Equations 4, 5. As the discharge rate increased, the heat generation also increased, and the difference in heat generation also appeared depending on the environmental temperature. The heat generation was calculated according to the changes in surface temperature, internal resistance, and entropy. At the overall environmental temperature, the heat generation increased as the temperature decreased, and at the $1 \mathrm{C}$, it increased from 7.16 to $25.1 \mathrm{~W}$. At the $2 \mathrm{C}$, the heat generation increased by 20.6-81.0 W, and at the $3 \mathrm{C}$, the heat generation increased by $32.5-151.5 \mathrm{~W}$. The high heat generation at -30 and $-20^{\circ} \mathrm{C}$ is because the heat generation on the surface of the battery is more than $5^{\circ} \mathrm{C}$ compared to the fast discharging time.

Figure 6 plots the heat generation against the nondimensional discharge factor which compares of discharge rate with non-dimensional temperature. The non-dimensional temperature is defined as follows.

$$
T^{*}=\frac{T}{293}
$$

It has been found that the heat generation is proportional to the cubic root of discharge rate while it is irreversibly proportional to the non-dimensional temperature. The resulting relationship can be described in.

$$
\log Q=-1.77+3.9 \frac{C^{1 / 3}}{T^{*}}
$$

As far as the authors know, the proposed equation is firstly presented in scientific society. Eq. 8 will be also generalized depending on the specification of the designed battery. In addition, the relationship provides the groundwork for predicting heat generation as well as pre-determining battery cooling system capacity.
Figure 7 shows the discharge efficiency according to the environmental temperature for each discharge rate through the discharge time of the battery. It was found that the discharge efficiency was critically decreased at the sub-zero environmental temperature, and the interval of the discharge efficiency also tended to increase. In the experiment with a discharge rate of $1 \mathrm{C}$, the environmental temperature with the highest discharge efficiency was 30 and $40^{\circ} \mathrm{C}$, and it was calculated as 87.3 and $87.4 \%$ with a difference of 0.1 . It was calculated to be $88 \%$ at $40^{\circ} \mathrm{C}$ at the $2 \mathrm{C}$ and $88 \%$ at $40^{\circ} \mathrm{C}$ at the $3 \mathrm{C}$. A comparison of the discharge efficiency shows that the higher the discharge rate, the greater the influence on the environmental temperature, and the higher the environmental temperature, the higher the performance of the battery.

\section{Temperature Variation of the Battery Surface}

Table 3 shows the average temperature change of the battery surface according to the change in environmental temperature and discharge rate. Except for $-30 /-20^{\circ} \mathrm{C}$ at the $3 \mathrm{C}$, it can be observed that the surface average temperature increases as the environmental temperature decreases.

Figure 8 shows the data with the uncritical and critical changes in the battery surface temperature change for the forward and backside surfaces at the discharge rates of 1-3 C. It was found that the change in the surface temperature of the battery decreased as the environmental temperature increased, regardless of the change in the discharge rate, except for the discharge rate of $3 \mathrm{C}$. Because the internal resistance decreased as the environmental temperature increased, the change in the surface temperature decreased under the experimental conditions. Figure 8A shows the battery surface temperature change for each environmental temperature at the $1 \mathrm{C}$, and the uncritical temperature change at an environmental temperature of $40^{\circ} \mathrm{C}$ was $2.35^{\circ} \mathrm{C} / 2.25^{\circ} \mathrm{C}$; the temperature change was measured from the forward/backside. The critical temperature change was at the environmental temperature of $-30^{\circ} \mathrm{C}$, and the temperature change was measured at the forward/backside at $6.3^{\circ} \mathrm{C} / 6.93^{\circ} \mathrm{C}$. A difference of $4.68^{\circ} \mathrm{C}$ was calculated for the battery surface temperature change with respect to the environmental temperature. Figure 8B shows the battery surface temperature change for each environmental temperature at the $2 \mathrm{C}$, and the uncritical temperature change at an environmental temperature

\begin{tabular}{|c|c|c|c|}
\hline & $1 \mathrm{C}$-rate $\left({ }^{\circ} \mathrm{C}\right)$ & 2 C-rate $\left({ }^{\circ} \mathrm{C}\right)$ & $3 \mathrm{C}$-rate $\left({ }^{\circ} \mathrm{C}\right)$ \\
\hline$-30^{\circ} \mathrm{C}$ & 5.7 & 10.6 & 5.0 \\
\hline$-20^{\circ} \mathrm{C}$ & 4.1 & 8.7 & 6.6 \\
\hline$-10^{\circ} \mathrm{C}$ & 3.2 & 8.3 & 10.8 \\
\hline $0^{\circ} \mathrm{C}$ & 2.7 & 6.7 & 9.9 \\
\hline $10^{\circ} \mathrm{C}$ & 2.2 & 5.2 & 9.5 \\
\hline $20^{\circ} \mathrm{C}$ & 2.1 & 4.6 & 7.8 \\
\hline $30^{\circ} \mathrm{C}$ & 2.1 & 4.0 & 6.9 \\
\hline $40^{\circ} \mathrm{C}$ & 1.7 & 3.7 & 6.5 \\
\hline
\end{tabular}
of $40^{\circ} \mathrm{C}$ was $4.53^{\circ} \mathrm{C} / 4.29^{\circ} \mathrm{C}$; the temperature change was measured 

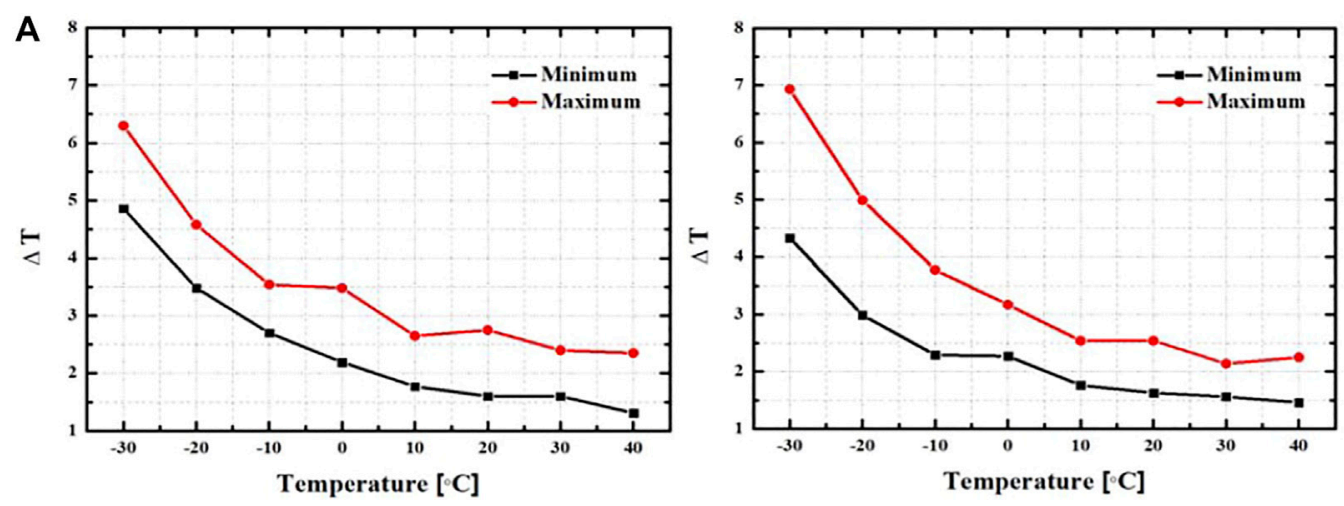

1 C-rate [Forward and backside surface]

B

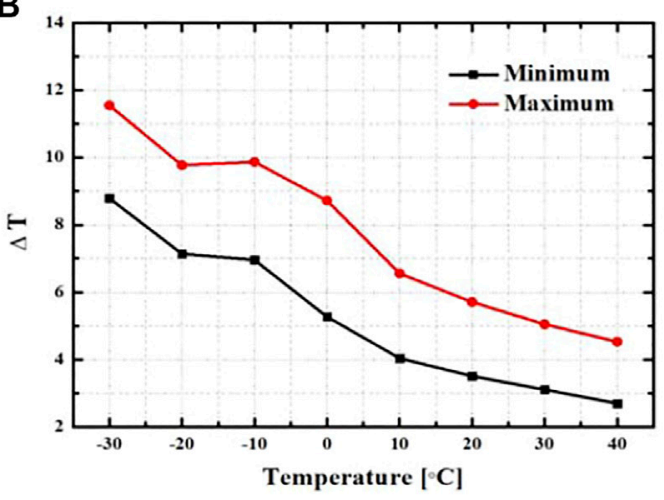

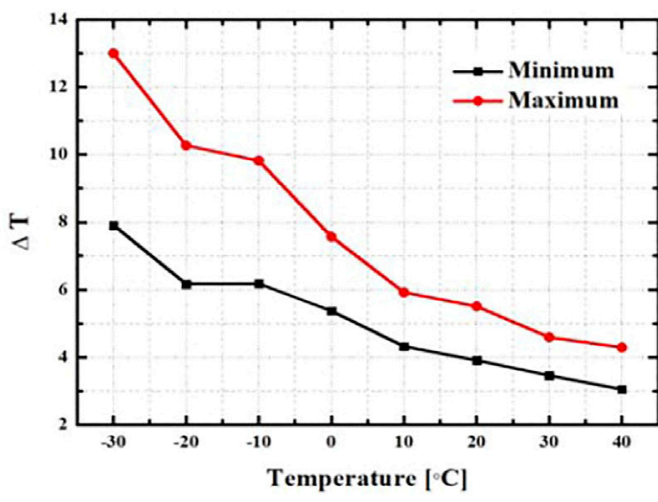

2 C-rate [Forward and backside surface]

C
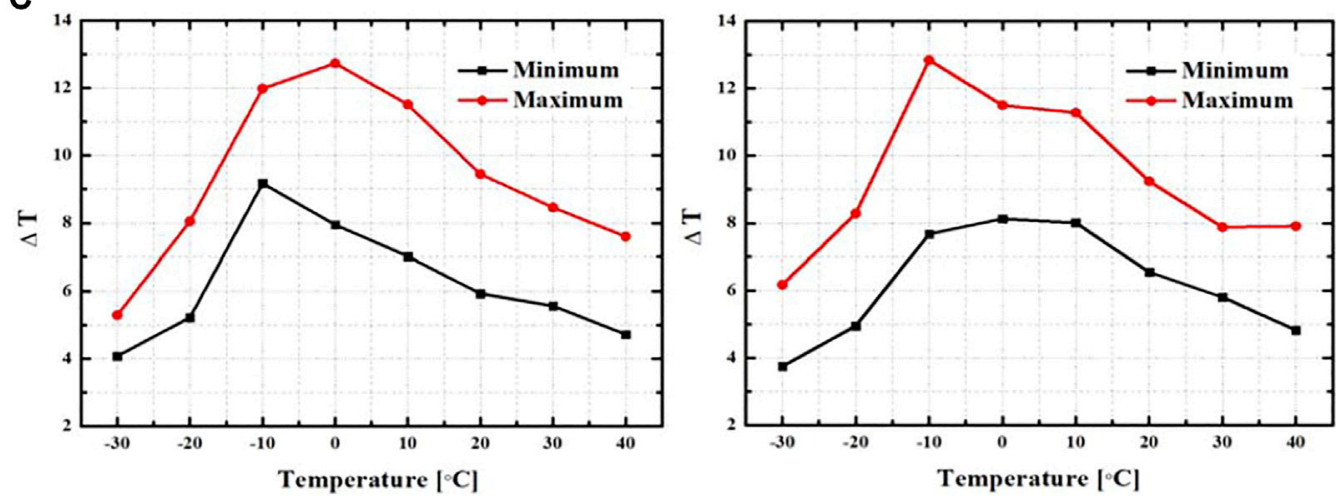

3 C-rate [Forward and backside surface]

FIGURE 8 | Temperature variation of critical and uncritical location. (A) 1 C-rate (Forward and backside surface). (B) 2 C-rate (Forward and backside surface). (C) 3 C-rate (Forward and backside surface).

from the forward/backside. The critical temperature change was at the environmental temperature of $-30^{\circ} \mathrm{C}$, and the temperature change was measured from the forward/backside as $11.55^{\circ} \mathrm{C} / 13^{\circ} \mathrm{C}$.
A difference of $8.11^{\circ} \mathrm{C}$ was calculated for the battery surface temperature change with respect to the environmental temperature. Figure 8C shows the battery surface temperature 
change for each environmental temperature at the $3 \mathrm{C}$, and the uncritical temperature change at the environmental temperature of $-30^{\circ} \mathrm{C}$ was $5.29^{\circ} \mathrm{C} / 6.17^{\circ} \mathrm{C}$; the temperature change was measured from the forward/backside. The critical temperature change was measured as $12.73^{\circ} \mathrm{C}$ at the forward side of the environment temperature of 0 and $12.84^{\circ} \mathrm{C}$ at the backside of the environment temperature of $-10^{\circ} \mathrm{C}$. A maximum difference of $6.67^{\circ} \mathrm{C}$ was calculated for the battery surface temperature change with respect to the environmental temperature.

Based on the experimental results, Figures 4, 5, 8 showed that there is an internal change in the battery as the environmental temperature changes (Baronti et al., 2010). The experiment was not conducted at an environmental temperature of $40^{\circ} \mathrm{C}$ or higher considering the thermal runaway. From the numerical analysis results of (Kwon and Park, 2019), it may be confirmed that the battery performance increases as the environmental temperature increases in a single cycle but the battery performance is degraded as multiple cycles progress. The effect on battery performance and temperature change according to the battery environmental temperature and discharge rate was experimentally studied in this paper. Further investigations will be conducted in regard to the multiple charge and discharge cycle performances with different environmental temperature.

In this study, the battery performance and surface temperature change based on the environmental temperature and discharge rate of the lithium-polymer battery were tested. According to the experimental results, the critical battery surface temperature change was $6.9^{\circ} \mathrm{C}\left(\right.$ At $\left.1 \mathrm{C},-30^{\circ} \mathrm{C}\right) / 13^{\circ} \mathrm{C}\left(\right.$ At $\left.2 \mathrm{C},-30^{\circ} \mathrm{C}\right) / 12.8^{\circ} \mathrm{C}$ (At $3 \mathrm{C},-10^{\circ} \mathrm{C}$ ) based on the environmental temperature and each discharge rate, the highest average heat generation was measured as $25.1 \mathrm{~W} / 81.0 \mathrm{~W} / 151.5 \mathrm{~W}$ (At $1,2,3 \mathrm{C},-30^{\circ} \mathrm{C}$ ), and the high discharge efficiency was $88 \%$ (At $2,3 \mathrm{C}, 40^{\circ} \mathrm{C}$ ). Through the analysis of the experimental results, it is suggested that the performance of the battery is correlated with the environmental temperature and the discharge rate and is an important factor.

\section{CONCLUSION}

In this study, the following conclusions were drawn through experiments based on the changes in the environmental temperature and discharge rate of high-discharge lithiumpolymer batteries.

1) At the discharge rates of 1 and $2 \mathrm{C}$, the discharge performance is more than $70 \%$ except at below zero 20 and $30^{\circ} \mathrm{C}$, and the discharge performance at the discharge rate of $3 \mathrm{C}$ is less than

\section{REFERENCES}

Al-Zareer, M., Dincer, I., and Rosen, M. A. (2018). A Review of Novel thermal Management Systems for Batteries. Int. J. Energ. Res. 42, 3182-3205. doi:10.1002/er. 4095

Amjad, S., Neelakrishnan, S., and Rudramoorthy, R. (2010). Review of Design Considerations and Technological Challenges for Successful Development and
$70 \%$ at under $0^{\circ} \mathrm{C}$, so there is a difference in discharge performance and influence according to environmental temperature and discharge rate.

2) At the discharge rate of $3 \mathrm{C}$, the influence on the average internal resistance and average entropy change of the battery according to the environmental temperature was found to be the highest.

3) The uncritical and critical heat generation was about $7 \mathrm{~W}$ (At $1 \mathrm{C}, 20,30,40^{\circ} \mathrm{C}$ ) and $151.5 \mathrm{~W}\left(\right.$ At $\left.3 \mathrm{C},-30^{\circ} \mathrm{C}\right)$.

4) At an environmental temperature of $40^{\circ} \mathrm{C}$, where the change in battery discharge performance and surface temperature is the lowest, the discharge efficiency was calculated with $87.4 \%$ (1 C), $88 \%$ (2 C), and $88 \%$ (3 C).

Through this study, it was found that the heat generation is correlated to the discharge rate and environmental temperature with the relationship of $\log Q=-1.77+3.9 \frac{C^{3}}{T^{*}}$. This relationship will be practically useful in designing thermal management system for battery powered devices.Conflict of Interest

The authors declare that the research was conducted in the absence of any commercial or financial relationships that could be construed as a potential conflict of interest.

\section{DATA AVAILABILITY STATEMENT}

The original contributions presented in the study are included in the article/Supplementary Material, further inquiries can be directed to the corresponding author.

\section{AUTHOR CONTRIBUTIONS}

JC and HP conceived the idea and designed the experiment. JC and HP jointly described and conducted experiments on battery performance changes in environmental temperature and heat generation. JC analyzed the data and wrote the manuscript. HP supported the manuscript preparation.

\section{FUNDING}

This work was supported by the National Research Foundation of Korea (NRF) grant funded by the Korea government (MSIT). (No. NRF-2019R1A2C1002212).

Deployment of Plug-In Hybrid Electric Vehicles. Renew. Sust. Energ. Rev. 14, 1104-1110. doi:10.1016/j.rser.2009.11.001

Bahiraei, F., Fartaj, A., and Nazri, G.-A. (2017). Electrochemical-thermal Modeling to Evaluate Active thermal Management of a Lithium-Ion Battery Module. Electrochimica Acta 254, 59-71. doi:10.1016/j.electacta. 2017.09.084

Baronti, F., Fantechi, G., Leonardi, E., Roncella, R., and Saletti, R. (2010). "Enhanced Model for Lithium-Polymer Cells Including Temperature 
Effects," in IECON 2010-36th Annual Conference on IEEE Industrial Electronics Society, Glendale, November 7-10, 2010. 2329-2333. doi:10. 1109/IECON.2010.5675134

Cao, J., Feng, J., Fang, X., Ling, Z., and Zhang, Z. (2021). A Delayed Cooling System Coupling Composite Phase Change Material and Nano Phase Change Material Emulsion. Appl. Therm. Eng. 191, 116888. doi:10.1016/j.applthermaleng.2021. 116888

Ghadbeigi, L., Day, B., Lundgren, K., and Sparks, T. D. (2018). Cold Temperature Performance of Phase Change Material Based Battery thermal Management Systems. Energ. Rep. 4, 303-307. doi:10.1016/j. egyr.2018.04.001

Huang, R., Li, Z., Hong, W., Wu, Q., and Yu, X. (2020). Experimental and Numerical Study of PCM Thermophysical Parameters on Lithium-Ion Battery thermal Management. Energ. Rep. 6, 8-19. doi:10.1016/j.egyr.2019.09.060

International Energy Agency (2020). Global EV Outlook 2020. Available at: https://www.oecd-ilibrary.org/energy/global-ev-outlook-2020_d394399een/ (Accessed January 5, 2021).

Jeon, D. H., and Baek, S. M. (2011). Thermal Modeling of Cylindrical Lithium Ion Battery during Discharge Cycle. Energ. Convers. Manage. 52, 2973-2981. doi:10.1016/j.enconman.2011.04.013

Jilte, R. D., and Kumar, R. (2018). Numerical Investigation on Cooling Performance of Li-Ion Battery thermal Management System at High Galvanostatic Discharge. Eng. Sci. Technol. Int. J. 21 (5), 957-969. doi:10.1016/j.jestch.2018.07.015

Kalkan, O., Celen, A., Bakirci, K., and Dalkilic, A. S. (2021). Experimental Investigation of thermal Performance of Novel Cold Plate Design Used in a Li-Ion Pouch-type Battery. Appl. Therm. Eng. 191, 116885. doi:10.1016/j. applthermaleng.2021.116885

Kshetrimayum, K. S., Yoon, Y.-G., Gye, H.-R., and Lee, C.-J. (2019). Preventing Heat Propagation and thermal Runaway in Electric Vehicle Battery Modules Using Integrated PCM and Micro-channel Plate Cooling System. Appl. Therm. Eng. 159, 113797. doi:10.1016/j.applthermaleng.2019.113797

Kwon, H., and Park, H. (2019). Numerical Simulation of Prismatic Lithium-Ion Battery Life Cycles under a Wide Range of Temperature. Int. J. Precis. Eng. Manuf.-Green Tech. 6, 63-73. doi:10.1007/s40684-019-00034-3

Li, M., Lu, J., Chen, Z., and Amine, K. (2018). 30 Years of Lithium-Ion Batteries. Adv. Mater. 3033, 1800561. doi:10.1002/adma.201800561

McKerracher, C. (2020). Electric Vehicle Outlook 2020. Available at: https://about. bnef.com/electric-vehicle-outlook/ (Accessed Jan 5th, 2021).

Monika, K., Chakraborty, C., Roy, S., Dinda, S., Singh, S. A., and Datta, S. P. (2021). Parametric Investigation to Optimize the thermal Management of Pouch Type Lithium-Ion Batteries with Mini-Channel Cold Plates. Int. J. Heat Mass Transfer 164, 120568. doi:10.1016/j.ijheatmasstransfer.2020.120568

Panchal, S., Dincer, I., Agelin-Chaab, M., Fraser, R., and Fowler, M. (2018). Design and Simulation of a Lithium-Ion Battery at Large C-Rates and Varying Boundary Conditions through Heat Flux Distributions. Measurement 116, 382-390. doi:10.1016/j.measurement.2017.11.038

Patil, M. S., Seo, J.-H., Panchal, S., Jee, S.-W., and Lee, M.-Y. (2020). Investigation on Thermal Performance of Water-Cooled Li-Ion Pouch Cell and Pack at High
Discharge Rate with U-Turn Type Microchannel Cold Plate. Int. J. Heat Mass Transfer 155, 119728. doi:10.1016/j.ijheatmasstransfer.2020.119728

Requia, W. J., Mohamed, M., Higgins, C. D., Arain, A., and Ferguson, M. (2018). How Clean Are Electric Vehicles? Evidence-Based Review of the Effects of Electric Mobility on Air Pollutants, Greenhouse Gas Emissions and Human Health. Atmos. Environ. 185, 64-77. doi:10.1016/j.atmosenv.2018.04.040

Sheng, L., Zhang, H., Zhang, H., Su, L., and Zhang, Z. (2021). Lightweight Liquid Cooling Based thermal Management to a Prismatic Hard-Cased Lithium-Ion Battery. Int. J. Heat Mass Transfer 170, 120998. doi:10.1016/j. ijheatmasstransfer.2021.120998

Suresh Patil, M., Seo, J.-H., and Lee, M.-Y. (2021). A Novel Dielectric Fluid Immersion Cooling Technology for Li-Ion Battery thermal Management. Energ. Convers. Manage. 229, 113715. doi:10.1016/j.enconman.2020. 113715

Talluri, T., Kim, T., and Shin, K. (2020). Analysis of a Battery Pack with a Phase Change Material for the Extreme Temperature Conditions of an Electric Vehicle. Energies 13, 507. doi:10.3390/en 13030507

Wang, N., Li, C., Li, W., Huang, M., and Qi, D. (2021). Effect Analysis on Performance Enhancement of a Novel Air Cooling Battery thermal Management System with Spoilers. Appl. Therm. Eng. 192, 116932. doi:10. 1016/j.applthermaleng.2021.116932

Wei, Y., and Agelin-Chaab, M. (2018). Experimental Investigation of a Novel Hybrid Cooling Method for Lithium-Ion Batteries. Appl. Therm. Eng. 136, 375-387. doi:10.1016/j.applthermaleng.2018.03.024

Wu, W., Wu, W., and Wang, S. (2017). Thermal Optimization of Composite PCM Based Large-Format Lithium-Ion Battery Modules under Extreme Operating Conditions. Energ. Convers. Manage. 153, 22-33. doi:10.1016/j.enconman. 2017.09.068

Zhang, G., Cao, L., Ge, S., Wang, C.-Y., Shaffer, C. E., and Rahn, C. D. (2014). In Situ measurement of Radial Temperature Distributions in Cylindrical Li-Ion Cells. J. Electrochem. Soc. 161, A1499-A1507. doi:10.1149/2.0051410jes

Conflict of Interest: The authors declare that the research was conducted in the absence of any commercial or financial relationships that could be construed as a potential conflict of interest.

Publisher's Note: All claims expressed in this article are solely those of the authors and do not necessarily represent those of their affiliated organizations, or those of the publisher, the editors, and the reviewers. Any product that may be evaluated in this article, or claim that may be made by its manufacturer, is not guaranteed or endorsed by the publisher.

Copyright $\odot 2022$ Choi and Park. This is an open-access article distributed under the terms of the Creative Commons Attribution License (CC BY). The use, distribution or reproduction in other forums is permitted, provided the original author $(s)$ and the copyright owner(s) are credited and that the original publication in this journal is cited, in accordance with accepted academic practice. No use, distribution or reproduction is permitted which does not comply with these terms. 